\title{
Constraints in household relocation: Modeling land-use/transport interactions that respect time and monetary budgets
}

\author{
Rolf Moeckel \\ Technical University of Munich \\ rolf.moeckel@udo.edu
}

\begin{abstract}
Traditionally, integrated land-use/transportation models intend to represent all opportunities of travel and household location, maximize utilities and find an equilibrium in which no person or household could improve their satisfaction any further. Energy scarcity, higher transportation costs, and an increasing share of low-income households, on the other hand, demand special attention to represent constraints that households face, rather than opportunities for utility maximization. The integrated land-use model SILO explicitly represents various constraints, including the price of a dwelling, the travel time to work, and the monetary transportation budget. SILO ensures that no household makes choices that violate these constraints. Implementing such constraints helps SILO to generate more realistic results under scenarios that put current conditions under a stress test, such as a serious increase in transportation costs or severely increased congestion.
\end{abstract}

\section{Article history:}

Received: January 18, 2015

Accepted: April 21, 2015

Available online: January 7, 2016

\section{Introduction}

Households looking for a new place to live attempt to fulfill as many of their location preferences as possible. At the same time, however, households face a couple of constraints in a housing search. First and foremost, the price of a new dwelling is a constraint. Even though loans and mortgages allow households to afford places that exceed their immediately available budget, households have to get along with their income in the long run. This is why low-income households cannot afford moving into the most sought-after houses on the market. Income is an obvious constraint on housing choice for almost every household.

Another constraint households face when looking for a new dwelling is travel time. An analysis of the 2007-2008 Household Travel Survey for the Baltimore/Washington region revealed that 86 percent of all workers travel less than 60 minutes to work, and 99 percent travel less than 120 minutes to work. Commuting for no more than two hours, therefore, is another constraint for most households, at least on a daily basis. Suitable home locations are even more restricted if more than one household member is working. As the average time spent on commuting does not change much over time (Zahavi, Beckmann, and Golob 1981), this constraint is unlikely to change much in the future. As a consequence,

Copyright 2015 Rolf Moeckel

http://dx.doi.org/10.5198/jtlu.2015.810

ISSN: 1938-7849 | Licensed under the Creative Commons Attribution - Noncommercial License 3.0

The Journal of Transport and Land Use is the official journal of the World Society for Transport and Land Use (WSTLUR) and is published and sponsored by the University of Minnesota Center for Transportation Studies. 
average workers should be expected to move closer to their work location if congestion worsens, unless they have the opportunity to telework.

Another constraint is constituted by the total household budget. According to the Consumer Expenditure Survey ${ }^{1}$, the average U.S. household spends 18.2 percent of its after-tax income on transportation. Should transportation become more expensive, households have to either adjust their travel behavior or reallocate their income. In reality, both happen. In some cases, particularly for low-income households, a steep increase in transportation costs may trigger a household relocation to a less expensive apartment to ensure that the household gets along with its income in the long run.

The literature review (Section 2) shows that the majority of land-use models do not represent such constraints explicitly. Section 3 introduces the land-use model SILO, and Section 4 explains how constraints are treated in SILO. Section 5 shows model validation results and Section 6 presents conclusions and recommendations for further research.

\section{Literature review}

One of the pioneering land-use models was designed by Herbert and Stevens (1960) in cooperation with Britton Harris as an equilibrium model simulating the distribution of households to residential land use. Lowry's model of metropolis (Lowry 1964, 1966) is often considered to be the first computer model that truly integrated land use and transportation. The Lowry model assumed the location of basic employment exogenously and generated an equilibrium for the allocation of non-basic employment and population. Over the last five decades, this popular model has been implemented many times (e.g., Batty 1976; Wang 1998; Mishra et al. 2011). At least equally influential was Forrester's Theory of Urban Interactions (1969). Even though it was an a-spatial model, this research on interactions between population, employment, and housing has influenced the design of many spatial land-use models developed since.

Putman developed the integrated transportation and land-use model package (ITLUP) (Putman 1983, 1991), where land use was modeled by the projective land-use model (PLUM) (Rosenthal, Meredith, and Goldner 1972; Goldner, Rosenthal, and Meredith 1972; Reynolds and Meredith 1972). Later, PLUM was replaced by the frequently applied disaggregated residential allocation model (DRAM) and an employment allocation model (EMPAL).

Wilson's entropy model $(1967,1970)$ generated an equilibrium by maximizing entropy of trips, goods flows, or the distribution of population. This model assumes a perfect equilibrium, which may never be reached in reality. Anas' (1982) model called the residential location markets and urban transportation created an equilibrium between demand, supply, and costs for housing. Anas' model, rather than follow the traditional deterministic approach that assigns each dwelling to the highest-paying buyer, instead applies stochastic variation to preferences and decisions.

The MEPLAN model developed by Echenique is an aggregated land-use transport model (Echenique, Crowther, and Lindsay 1969; Echenique et al. 1990; Abraham and Hunt 1999) that used the basic concept of the Lowry model as a starting point. The model can simulate a variety of both land-use and transport scenarios. MEPLAN has been applied to more than 25 regions worldwide (Hunt, Kriger, and Miller 2005, p. 332). Another modeling approach using the Lowry model as a starting point is the TRANUS model (de la Barra, 1989; de la Barra and Rickaby 1982; de la Barra, Perez, and Vera 1984) that simulates land use, transport, and its interactions at the urban and regional scale.

Martínez $(2002,1996)$ developed a land-use model under the acronym MUSSA in which location choice is modeled as a static equilibrium. Residential and commercial land-use developments compete for available land. MUSSA used the bid-auction approach based on the bid-rent theory where consumers try to achieve prices as low as possible and not higher than their willingness to pay (Martínez

${ }^{1}$ Available online at http://www.bls.gov/cex/\#tables 
1992). In the bid-rent theory, first introduced by Alonso (1964), land prices are an immediate result of the bid-auction process. In contrast, the discrete-choice approach—initially developed for housing choice by McFadden (1978) — models land being bought or rented with no instant effect on the price. Acknowledging that both approaches lead to similar results, Martínez argues elsewhere (1992) that the bid-auction approach and the discrete-choice approach should be integrated and seen as inseparable rather than opposed.

Wegener $(1999,1998 b, 1982)$ developed the IRPUD model as a fully integrated land-use transport model. The household location choice is microscopic (Wegener 1984), simulating every household individually. The IRPUD model was one of the few early approaches that contradicted the common assumption that land-use models shall reach an equilibrium at the end of each simulation period (Wegener, Gnad, and Vannahme 1986). Land-use development aims at equilibrium constantly, but due to a continuously changing environment and slow reaction times of households, businesses, developers, and planners, this equilibrium stage is never reached. The price of a new dwelling and the commute distance to the household's main workplace are accounted for as true constraints in location choice. Similarly, the metroscope model for Portland, Oregon, (Conder and Lawton, 2002) compares expenditures for housing, transportation, food, health, and all other expenses to ensure that household budgets are not exceeded.

PECAS (Hunt and Abraham 2009, 2003) is another land-use model that represents an equilibrium of competing demand for developable land. Households relocate based on available floor space, prices, accessibilities, and other location factors. PECAS combines this bid-rent approach in a spatial economic model with a microscopic land-development model. DELTA (Simmonds and Feldman 2007) combines an economic model with households and job location model and a long-distance migration model.

Microsimulation was introduced by Orcutt et al. (1961) and subsequently applied to a series of modeling tasks, including travel behavior, demographic change, spatial diffusion, health and land use (Clarke and Holm 1987). The most influential microscopic land-use models include the California urban futures (CUF) model (Landis and Zhang 1998a, 1998b), the integrated land-use, transport and environment (ILUTE) model (Miller et al. 2004; Miller and Salvini 2001; Salvini and Miller 2003), the urban simulation (UrbanSim) model (Waddell 2002; Waddell et al. 2003), the learning-based transportation oriented simulations system (ALBATROSS) (Arentze and Timmermans 2000), predicting urbanization with multi-agents (PUMA) (Ettema et al. 2004), SimDELTA (Simmonds and Feldman, 2007) and the integrated land-use model and transportation system simulation (ILUMASS) (Strauch et al. 2005, Wagner and Wegener 2007). A common problem in microscopic modeling is stochastic variability between model runs. Gregor (2006) overcame this shortcoming in the land-use scenario developer (LUSDR) by running the same model hundreds of times and storing each model run as a potential future development.

Good overviews of operational land-use/transport models are given particularly by Hunt, Kriger, and Miller (2005), Wegener (2004, 1998a, 1994), Wegener and Fürst (1999), Timmermans (2003), Kanaroglou and Scott (2002), the U.S. Environmental Protection Agency (2000), and Kain (1987). The literature review showed that most land-use models do not explicitly represent constraints. The majority of models employ equilibrium methods to reach an "ideal" distribution of households and land uses. Commonly, land use is viewed as a decision-making process in which users optimize their utilities, rather than making choices among a limited set of alternatives. Notable exceptions are the IRPUD model and metroscope, which explicitly constrain households to move to dwellings that are within their respective price range. 


\section{The land-use model SILO}

SILO was designed as a microscopic discrete choice model. Every household, person, and dwelling is treated as an individual object. All decisions that are spatial in nature (household relocation and development of new dwellings) are modeled with Logit models. Initially developed by Domencich and McFadden (1975), such models are particularly powerful at representing the psychology behind decision making under uncertainty. Other decisions (such as getting married, giving birth to a child, leaving the parental household, renovating a dwelling, etc.) are modeled with Markov models by applying transition probabilities.

SILO is integrated with the Maryland Statewide Transportation Model (MSTM) to fully represent interactions between land use and transportation. The model is built to work with less rigorous data collection and estimation requirements than traditional large-scale land-use models. Rather than requiring costly data collection and time-consuming model estimation, SILO takes advantage of national averages where possible and transfers parameters from models that have been implemented elsewhere. Figure 1 provides an overview of the SILO model.

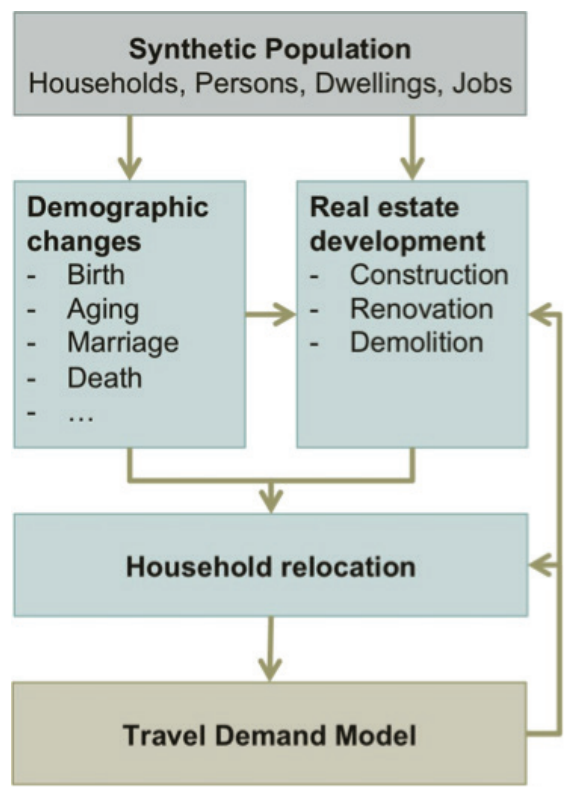

Figure 1: Flowchart of the land-use model SILO

At the beginning, a synthetic population is created for the base year 2000. The U.S. Census Public Use Micro Sample (PUMS) 5 percent dataset ${ }^{2}$ is used to create this synthetic population. Using expansion factors provided by PUMS, household records including dwellings are duplicated until the population by PUMS zone (called a PUMA) matches 2000 census data. The location is disaggregated from PUMA to model zones using the zonal socioeconomic data of the MSTM as weights. Work places are created based on MSTM zonal employment data. For each worker, a work location is chosen within the recorded work-PUMA and based on the average commute trip length distribution found in the 20072008 Household Travel Survey for the Baltimore/Washington region. SILO simulates events that may occur to persons, households, and dwellings:

The housing market is modeled explicitly. Vacancy rates by five dwelling types and 31 regions are used as a proxy for additional demand. If vacancy rates drop, developers will add additional dwellings if zoning permits. To find the best locations for new dwellings, developers mimic the location choice

\footnotetext{
${ }^{2}$ Available for download at http://www2.census.gov/census_2000/datasets/PUMS/FivePercent/
} 
behavior of households, and thereby, developers are likely to build the most marketable new dwellings. New dwellings are released into the housing market with a one-year delay to account for the time required for planning, approval, and construction. A hedonic price model is used to model changes in housing costs. Low vacancy rates lead to a fairly quick upward adjustment of prices, while high vacancies lead to a gradual price reduction. This reflects observed behavior that landlords use to attempt to keep prices high, even if demand is rather low.

Table 1: List of events simulated in SILO

\begin{tabular}{|l|l|}
\hline Household \\
\hline Relocation & Buy or sell cars \\
\hline Person & Divorce \\
\hline Aging & Death \\
\hline Leave parental household & Find a new job \\
\hline Marriage & Quit a job \\
\hline Birth to a child & Demolition \\
\hline Dwelling & Increase or decrase of housing price \\
\hline Construction of new dwellings & \\
\hline Renovation & \\
\hline Deterioration &
\end{tabular}

From one year to the next, certain events may trigger other events. For example, if a child is born, the household will have a higher probability of moving to a larger dwelling. Within one year, however, events are modeled in random order to avoid path dependency. A random number is assigned to each event. Events are sorted by this number in ascending order and executed in this sequence.

SILO is set to match observed land-use changes from 2000 to 2012 (so-called back-casting) and validated in 2012. Currently, the model runs to 2040 . While the entire model is fully operational, the remainder of this paper focuses on household relocation for which constraints are implemented explicitly.

The model covers demographic changes, household relocation, and real estate changes. Workplaces and commercial floor space are not modeled explicitly at this point but exogenously given based on the Financially Constrained Long-Range Transportation Plan (CLRP). In the future, it is planned to add a sub-model that simulates the employment side.

SILO is open-source software and was initially developed with research funding by Parsons Brinckerhoff, Inc. The prototype application was implemented for the metropolitan area of Minneapolis-St. Paul, Minnesota. Currently, the Maryland Department of Transportation supports the implementation of an improved version for Maryland. The acronym stands for "simple integrated land-use orchestrator," as the model is meant to be implemented more easily than traditional large-scale models that require extensive model estimation. A visualization tool is included for the analysis of model results. Further information on model design and implementation can be found at www.silo.zone.

\section{$4 \quad$ Modeling constraints}

SILO distinguishes location factors that are desirable and those that are essential. Finding a place to live within someone's housing budget, for example, is considered to be an essential location factor. Having a particularly large apartment, on the other hand, is a desirable location factor only. If all other location factors are excellent, a household might compromise dwelling size.

In contrast to desirable utilities, essential utilities are assumed to be mandatory to be fulfilled. The three essential location factors represented by SILO include housing costs, commute travel times, and 
transportation costs. If one of these three utilities is 0 , the utility for the entire dwelling has to be 0 . This is achieved by using the Cobb-Douglas function that aggregates utilities by multiplication.

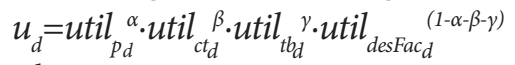

where:

$u_{d} \quad$ Utility of dwelling $d$

util $_{P_{d}} \quad$ Utility of the price $p$ of dwelling $d$ (see Section 4.1)

util $_{c_{d}} \quad$ Utility of the commute time $c t$ from dwelling $d$ (see Section 4.2)

$u t i l_{t b_{d}} \quad$ Utility of the transportation budget $t b$ required for dwelling $d$ (see Section 4.3)

util $_{d e s F a c_{d}}^{d}$ Utility of non-essential factors of dwelling $d$ (see Section 4.4)

$\alpha, \beta, \gamma \quad$ Parameters as weights for each factor, set differently by household type

This way, it is ensured that households do not move into a place that violates a budget constraint. The following sections describe the three essential location factors (Sections 4.1 to 4.3) and desirable location factors (Section 4.4).

\subsection{Housing cost constraints}

The costs of a dwelling form an immediate constraint for any relocation choice. While households may exceed their housing budget temporarily, households have to get along with their income in the long run. The distribution of rent and mortgage payments in the base year, according to PUMS data, is used as guidance on how much households are willing to pay for housing. Figure 2 shows the aggregation to reveal the willingness to pay rent or to pay for a mortgage. As expected, higher income households tend to pay more for housing than low-income households.

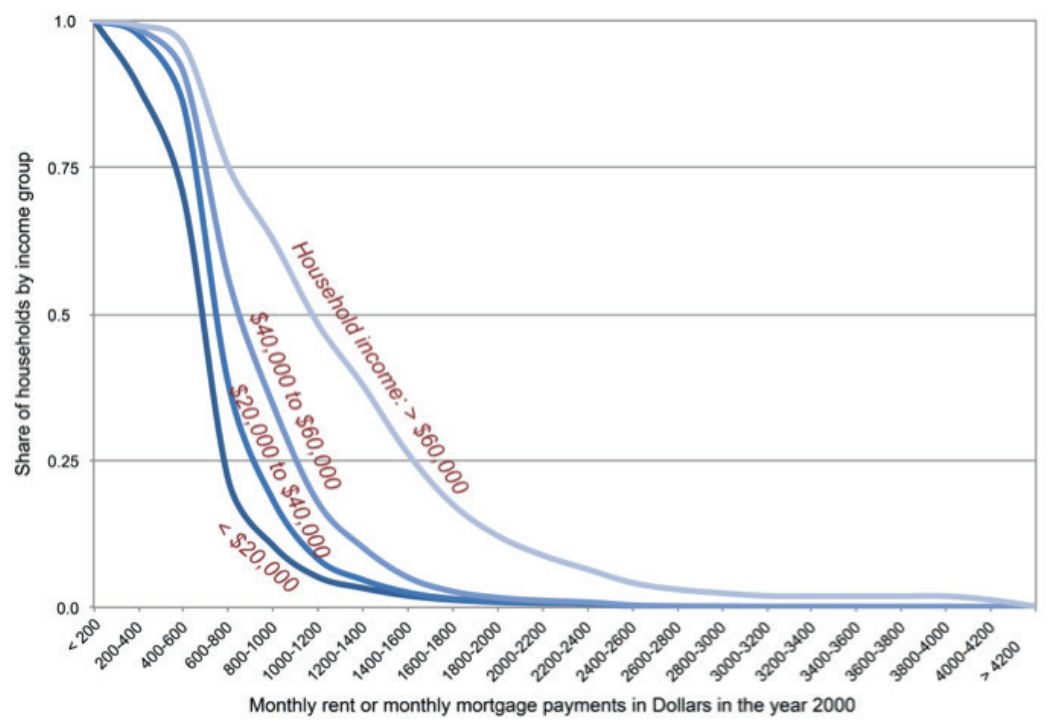

Figure 2: Willingness to pay rent by household income Source: PUMS 2000 database

The relationship between income and housing expenses shown in Figure 2 is used to calculate the utility of a given price using equation 2 . 


$$
\begin{aligned}
& \text { util }_{p \bar{d}}=1-\sum_{\text {price }_{j}}^{\text {price }_{j}<\text { price }_{d}} \text { hhShare }_{\text {price }_{j} \text { inc }} \\
& \text { where: } \\
& \text { util } \quad \text { Utility of price } p \text { of dwelling } d \\
& \text { hhShare }_{\text {price }, \text { inc }} \text { Share of households with income inc who have paid price }{ }_{j} \text { in the base year }
\end{aligned}
$$

The higher the price, the lower the utility, and the utilities decline faster for low-income households than for high-income households. When the price is high enough that the share of households paying this amount for housing reaches zero, the utility becomes zero, and that dwelling becomes unavailable for this household type.

\subsection{Commute travel time constraint}

The travel time to work is a primary driver for household location choice. With the exception of workers who regularly work from home, the travel time from home to work is an important constraint when choosing a new place to live. Travel time to work is remarkably constant over time (Zahavi, Beckman, and Golob 1981; van Wissen, Golob, and Meurs 1991). The aforementioned household travel survey for the Baltimore-Washington region was analyzed for the time spent on home-to-work trips. Because respondents tend to round their travel time to even numbers (for example, 12 percent reported their commute to be exactly 30 minutes), the observed trip length frequency distribution is lumpy and needs to be interpolated. Figure 3 shows the estimated gamma functions representing the observed trip length frequency distribution in minutes for commute trips. The gamma functions were calibrated to match the reported average travel time.

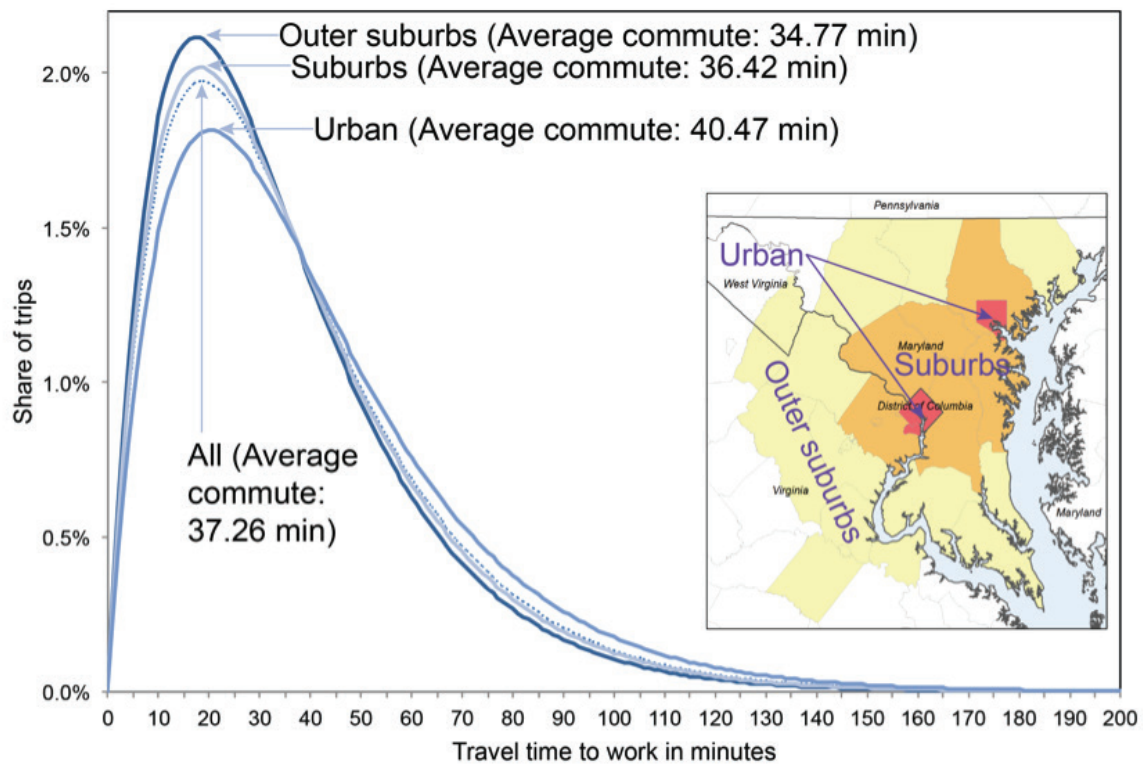

Figure 3: Estimated commute trip length frequency distributions in minutes for rural, suburban, and urban residents Source: 2007-2008 household travel survey for the Baltimore-Washington region

Residents living in the urban counties in Baltimore, Washington, Arlington, and Alexandria have above-average commute times. Even though their average commute trip lengths of 9.8 miles is shorter than the average commute trip length of outer suburbs residents ( 15.5 miles), urban densities lead to more congestion, and therefore, residents need more time to get to work. Also, the transit share is much 
higher in urban areas, which often leads to longer travel times. The trip length frequency distributions in minutes are expected to not change significantly in the future.

When households look for a new housing location, the job locations of all household members are taken into account. As SILO is designed as a microsimulation, the work locations of all household members are known. Dwellings that would result in a commute of more than 200 minutes for any worker in a household are given a utility of zero. It was confirmed with the survey that the average travel time per worker is almost identical (within 3 percent) for single-worker households and multiple-worker households, which allows application of the same trip length frequency distribution probabilities for all households. The left map in Figure 4 shows an example of a work location in North Bethesda, Maryland (turquoise dot). The trip length frequency distribution in minutes is used to estimate the utility in terms of commute distance for every zone (shown in brown-to-yellow colors).
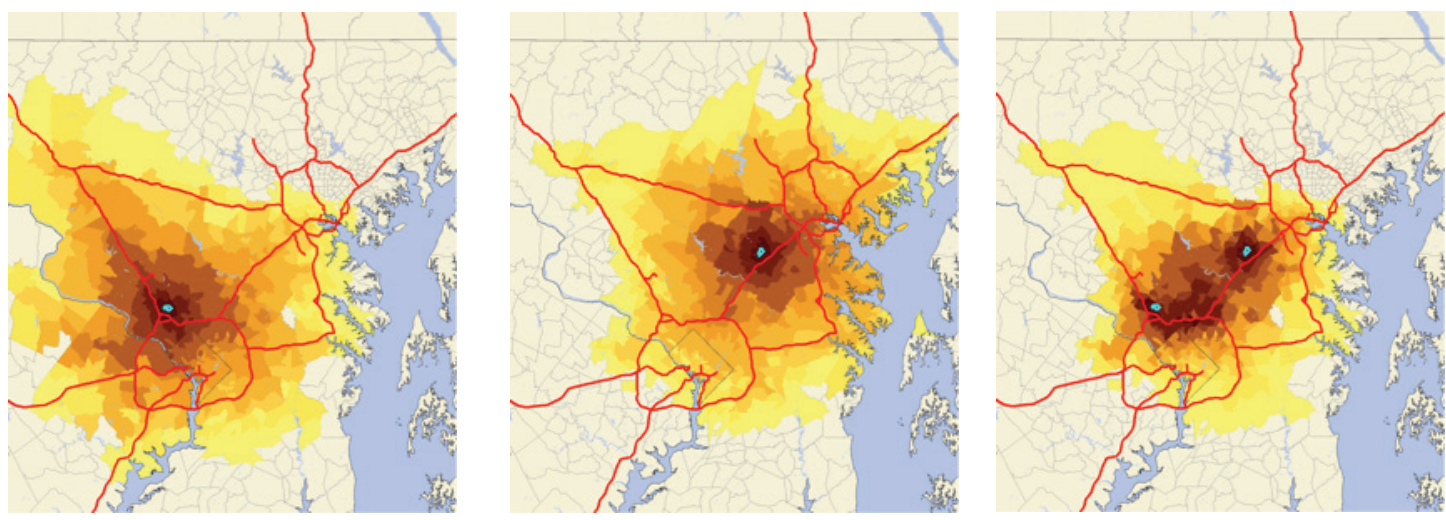

Figure 4: Likely housing locations for a household with workers in North Bethesda (left), Columbia (center), and both work locations (right)

The map in the center shows the home location probability for a person working in Columbia, Maryland. If these two persons lived in the same household, their joint area within a reasonable distance to their work locations is shown in the map on the right side of Figure 4. SILO explicitly represents this constraint when searching for a new housing location. The average commute trip length frequency in minutes shown in Figure 3 with a dotted line is scaled to values between 0 and 1 and applied as the commute distance utility.

Unfortunately, telework is not represented explicitly in SILO at this point. An employee working from home a few days per week is likely to be less constrained by the location of her or his employer and willing to accept longer commute travel times for the few days this person is actually commuting to work. It is planned to enhance the model to allow certain occupation types to telecommute, and thereby, offset some of their travel time budget.

Another shortcoming worth mentioning is that the constant travel time budget seems only to be reasonable with conventional modes of transportation. Should driverless cars become widely available, the value of time is expected to change substantially (Cyganski, Fraedrich, and Lenz 2015). Traveling in driverless cars may lessen the burden of commuting and thereby reduce this constraint in housing location in the future.

\subsection{Household budget constraint}

Another constraint explicitly reflected in SILO covers household expenditures. According to the Consumer Expenditure Survey ${ }^{3}$ of the Bureau of Labor Statistics, households spent an average of 18.2 per-

${ }^{3}$ Data available online at http://www.bls.gov/cex/home.htm 
cent of their after-tax income on transportation (fixed and variable costs) in 2000. Low-income households spent as much as 36.1 percent of their after-tax income on transportation. If transportation costs rise, these households will need to shift some expenses. While affluent households will simply reduce savings or discretionary spending to cover increased transportation costs, low-income households may struggle to cover substantially higher transportation costs. A household searching for a new home will at least roughly estimate transportation costs and consider carefully if transportation costs at a given home location are within the budget. A low-income household may decide to locate closer to the work location or choose a transit-friendly environment that may allow reducing the number of cars owned by the household.

Figure 5 compares average household income with average expenditures. The plot shows data for SILO's base year 2000, and data for 2005 and 2010 were analyzed and displayed very similar patterns. Interestingly, households in income categories with an annual after-tax income below $\$ 41,500$ spent, on average, more money than they earned. According to the Bureau of Labor Statistics, such households draw on savings or borrow money. Students may get by on loans, and retirees may rely on savings 4 . As SILO does not trace debts, a household may temporarily accumulate; it simply acknowledges that households have access to money to cover their expenses. For example, a household with an after-tax income of $\$ 7,192$ (left-most point in Figure 5) is assumed to have access to $\$ 15,703$ to spend.

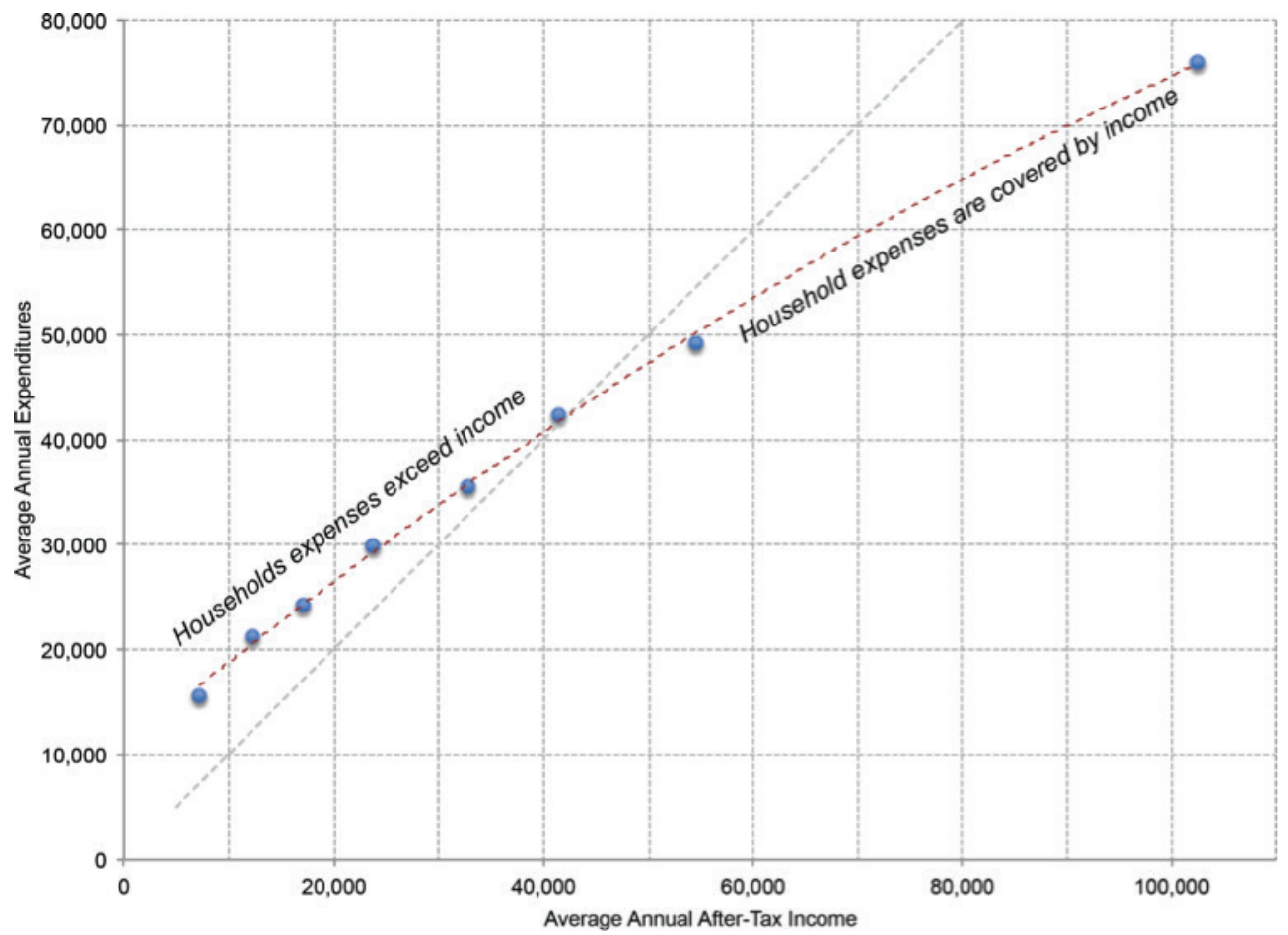

Figure 5: Household income and expenditures

Source: Consumer Expenditure Survey, BLS

A polynominal curve has been estimated to reflect the relationship between income and expenditures (shown with a red dashed line in Figure 5). For household incomes greater than $\$ 41,499$ (whose income exceeds expenditures), the entire income is assumed to be available for expenditures, even though the average household at that income level saves some money.

\footnotetext{
${ }^{4}$ For a more detailed discussion of this phenomenon compare http://www.bls.gov/cex/csxfaqs.htm\#q21
} 
$e_{h}=\max \left[i n c,\left(\alpha \cdot i n c_{h}^{2}+\beta \cdot i n c_{h}+\gamma\right)\right]$

where:

$e_{h} \quad$ Budget available for expenditures of household $h$

inc $c_{h} \quad$ Income of household $h$

$\alpha, \beta, \gamma \quad$ Parameters, estimated to $\alpha=-2 \mathrm{E}-6, \beta=0.8229$ and $\gamma=10,794$ [note that parameter names $\alpha, \beta$ and $\gamma$ are reused in several equations even though they relate to different parameter sets]

Due to the parameter $\gamma$, the available money for expenditures can never drop below $\$ 10,794$, even if the household income is reported as 0. According to the Consumer Expenditure Survey, expenses for gasoline and motor oil make up between 2.6 percent (for high income) and 3.9 percent (for low income) of all household expenses. Though this may not seem high, an increase of travel costs may become a serious burden for low-income households. Litman (2013) suggested that fuel price elasticity is between -0.1 and -0.2 for short-run and between -0.2 and -0.3 for medium-run adjustments. Short-run adjustments include choosing different trip destinations and switching the mode, while long-run adjustments (which typically apply after one to two years) include the purchase of more fuel-efficient vehicles and selecting more accessible home and job locations. Because a household move is part of a mediumto long-run adjustment, the higher elasticity with an average of -0.25 was chosen in SILO; should gas prices increase by 10 percent, travel demand is expected to decline by 2.5 percent. Transportation costs $t c$ are calculated based on auto-operating costs (set to 8.1 cents per mile in the base scenario), the distance to work, and transportation required for other purposes such as shopping, dropping off children at childcare, doctor visits, etc. For a scenario that analyzes the impact of higher fuel costs, the adjusted transportation expenditures are calculated by:

$$
\begin{array}{ll}
e t_{h}=t c_{s}\left(1+\frac{t c_{s}-t c_{r}}{t c_{r}} \cdot e l\right) \\
\text { where: } \\
e t_{h} \quad \text { Expenditures of household } h \text { for transportation } \\
t c \quad \text { Transportation costs ( } r \text { for reference case and } s \text { for alternative scenario) } \\
e l \quad \text { Elasticity of travel demand on transportation costs, set to }-0.25
\end{array}
$$

Currently, the elasticity is held constant, even though it is commonly assumed that elasticities rise as fuel prices increase. However, no data were readily available to quantify this relationship. Depending on future improvements in vehicle technology, the price per mile might drop, though increasing energy prices may offset technological advances. Currently, transportation costs per mile are kept unchanged from 2000 to 2040.

Costs for transit are not considered at this point, but auto travel costs are used as a proxy for the costs transit riders would face. This simplification is used for two reasons. First, the MSTM does not provide reliable transit fare values. In the future, general transit feed specification (GTFS) data are planned to replace existing transit networks, which is expected to overcome this shortcoming. Secondly, SILO does not know which mode of transport is going to be used by each traveler in the MSTM. While assumptions for zero-car households are easy (most of them will use transit), modal predictions for other households are difficult. However, given that transit fares are considered to be comparatively high in this region, the auto operating costs appear to be a reasonable proxy for transportation costs even for transit riders.

In addition to adjusting travel behavior and locations, many households will need to rebalance

\footnotetext{
${ }^{5}$ Assumed data points for income/discretionary spending: $[\$ 0 / \$ 100 ; \$ 20,000 / \$ 1000 ; \$ 40,000 / \$ 2200 ; \$ 100,000 / \$ 10,000$;
} $\$ 150,000 / \$ 20,000]$ 
expenditures if transportation costs rise. Figure 6 shows the relative size of various expenditure types. The total expenditure is identical to the expenditure line shown in Figure 5, and the shares of various expenditure categories were also estimated by polynominal functions using observations of the Consumer Expenditures Survey. A certain share of "other expenditures" is assumed to be discretionary (such as going out for dinner, going to the movie theater, vacationing, etc.) and could be used to offset increased transportation costs. No data were available to quantify discretionary spending, and a few data points ${ }^{5}$ were assumed to estimate a smooth curve for the discretionary spending shown in Figure 6.

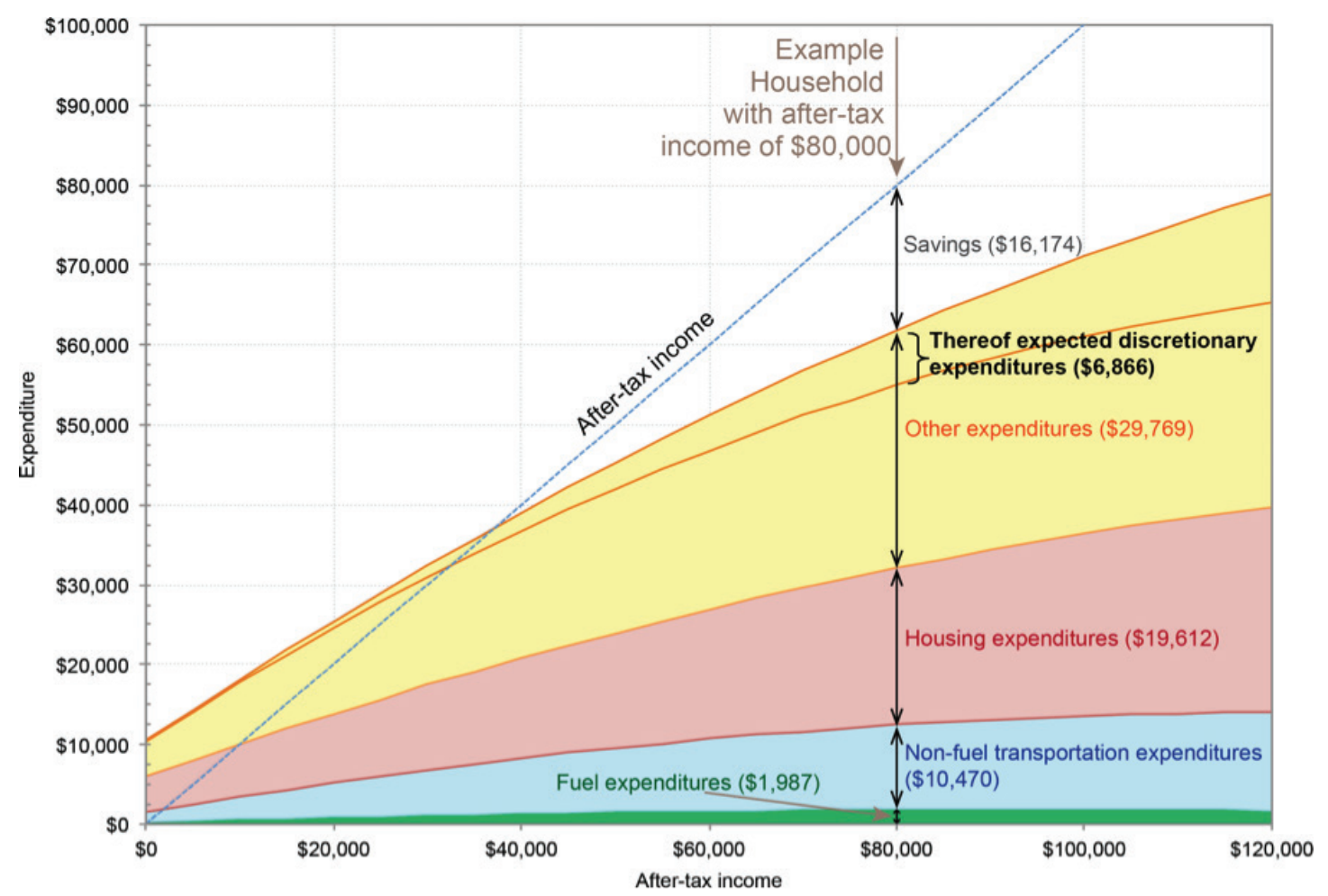

Figure 6: Share of expenditure types by household income

Source: Consumer Expenditure Survey, BLS

A binomial logit model (equation 5) is used to calculate the utility for transportation costs. If the discretionary income and savings are insufficient to cover the transportation costs of a given dwelling, the utility for transportation costs at this dwelling is set to 0 .

$$
\begin{aligned}
& \text { if }\left(e_{d i s, h}+s_{h}<\mathrm{tc}\right): \quad u t i l_{t b_{d}}=0 \\
& \text { if }\left(e_{d i s, h}+s_{h}<\mathrm{tc}\right): \quad \quad u t i l_{t b_{d}}=\frac{1}{1+\exp \left(\beta \cdot \frac{e_{d i s i s}+s_{h}}{t}\right)} \\
& \text { util }_{t b d} \quad \text { Utility of dwelling } \mathrm{d} \text { for transportations budget } \mathrm{tb} \\
& \beta \quad \text { Parameters describing sensitivity of increased transportation costs } \\
& e_{\mathrm{dis}, \mathrm{h}} \quad \text { Discretionary expenditures of household } h \\
& s_{h} \quad \text { Savings of household } h
\end{aligned}
$$

For high-income households, this utility will always be close to 1, as an increase in transportation costs is insignificant for these households. Households with a lower income, however, will find a lower 
utility if transportation costs at a given dwelling are high. Should transportation costs exceed the discretionary income plus savings, the utility for the dwelling will be set to 0 , which prevents this household from moving into this dwelling.

\subsection{Desirable location factors}

In addition to housing costs, commute travel times, and transportation costs (described in Sections 4.1 to 4.3), a number of further location attributes are included that are deemed to be desirable but nonessential. Such location factors include the size and the quality of the dwelling, the accessibility to population and employment by auto and transit, low crime rates, and the quality of schools in the school district of a dwelling. While these location factors are desirable, one strong attribute may compensate for another weak attribute. For example, a house in the suburbs may be weak in terms of accessibility but strong in terms of size. In contrast, urban apartments tend to be weaker in size, but provide excellent accessibilities. A strong attribute may offset a weak attribute, depending on the household preferences. Those location factors are combined by weighted addition.

$$
u_{t i l_{\text {desFac }}}=\alpha \cdot u_{\text {size }_{d}}+\beta \cdot u_{\text {quality }_{d}}+\gamma \cdot u_{\text {autoAcc }_{d}}+\delta \cdot u_{\text {transitAcc }_{d}}+\mathcal{\varepsilon} \cdot u_{\text {schoolQual }_{d}}+(1-\alpha-\beta-\gamma-\delta-\varepsilon) \cdot \text { util }_{\text {crimelndex }_{d}}
$$

where:

util $_{\text {desFac }_{d}}$ Utility of desirable (but nonessential) factors for dwelling $\mathrm{d}$

$\alpha, \beta, \gamma \ldots$ Parameters, set differently by household types

$u_{f_{\text {factord }}} \quad$ Utility of attribute of dwelling $d$ (currently implemented: size, quality, auto accessibility, transit accessibility, school quality, and county-level crime index)

\section{$5 \quad$ Sensitivity testing and model validation}

Validating land-use models tends to be more challenging than validating transportation models. While counts are generally perceived as sufficiently accurate to validate transportation models, no comparable dataset exists for land-use models. Two approaches were applied to validate SILO. First, sensitivity tests were conducted in which single parameters were modified and the changed model results were analyzed for reasonability. This is not considered to be a true validation in the traditional sense of comparing observed with modeled data, but it is rather a reasonability check. Such sensitivity tests have been completed for many variables, including parameters to calculate housing utilities, marriage and divorce probabilities, probability to leave the parental household, birth probabilities, initial housing vacancy rates, in-migration and out-migration assumptions, land capacity for future development, accessibility parameters, and auto-operating costs. Changes in model results were small and moved in the expected direction of change.

Secondly, rather than starting the model in a current base year, "back-casting" from 2000 to 2012 was applied. Figure 7 shows a scatter plot that compares observed and modeled number of households by county $\left(\mathrm{R}^{2}=0.991\right.$, RMSE $=10,107$, Percent RMSE $\left.=12.6\right)$. Modeled population numbers are the result of simulating 12 years in one-year increments, and observed population was collected from the five-year population estimate of the American Community Survey (ACS). Several counties in Maryland are slightly overestimated by the model, while Fairfax County (including Fairfax City and Falls Church City) falls short by 10 percent. This deviation along the state line is largely due to the fact that Maryland and Virginia have different methodologies of accounting for redevelopment opportunities (including greenfield development and infill development). Maryland traditionally has promoted denser develop- 
ment and has provided higher development capacity numbers than Virginia. Hence, the model expects more opportunities for growth in Maryland than in Virginia. It is investigated currently whether development capacities can be calculated by a unique method for the entire study area.

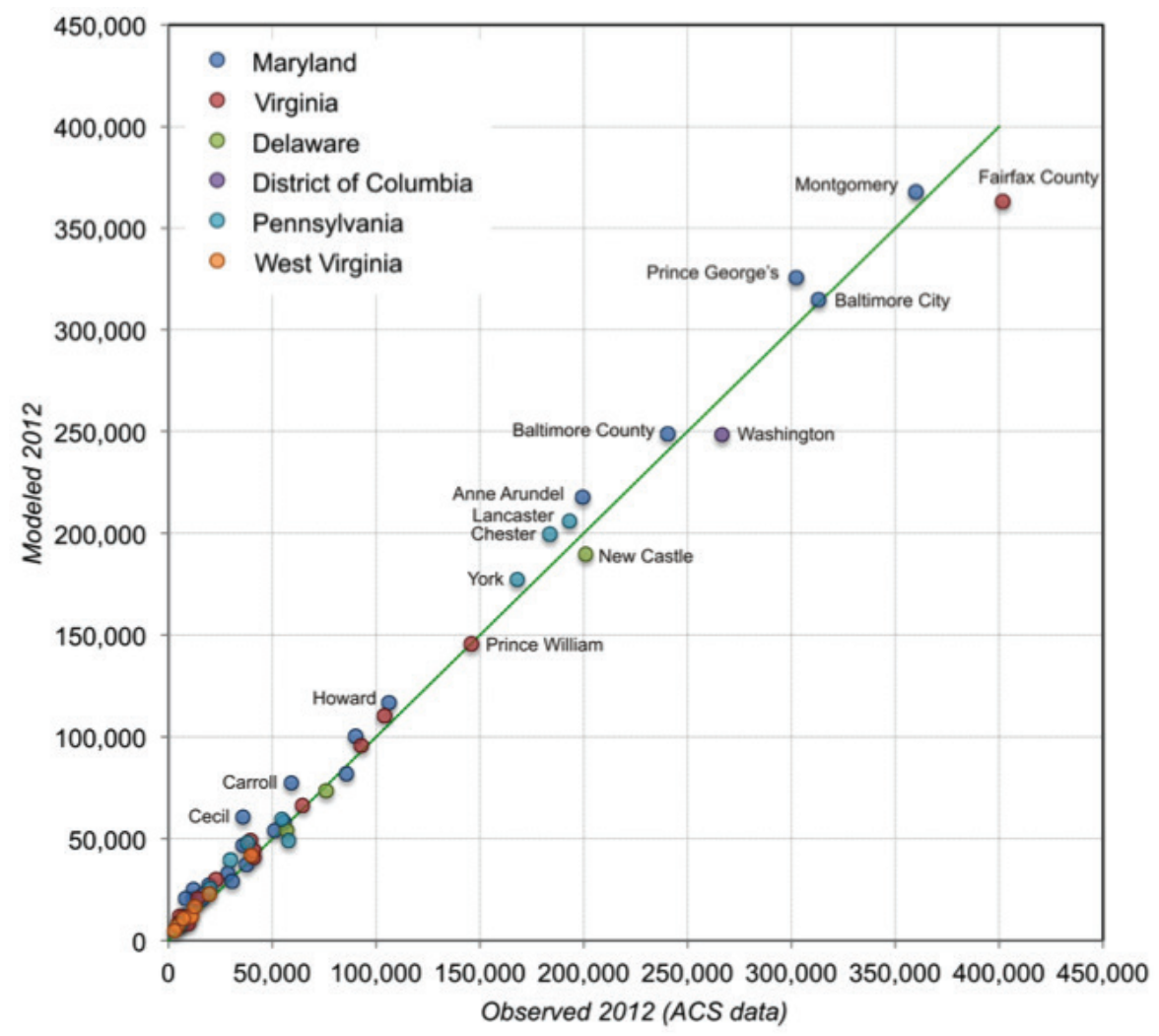

Figure 7: Validation of SILO results against 2012 ACS population data by county

SILO results were also compared at the zonal level against 2012 data from transportation models for Baltimore, Washington, DC, and Delaware. At this zonal level, an RMSE of 1123 and a Percent RMSE of 9 were found. The provenance of their zonal data is unknown, which is why this comparison does not count as validation but only as another reasonability check.

\section{Conclusions}

Many land-use models focus on representing utility maximization, finding equilibriums, and optimally allocating limited resources. The famous Lowry model was built to reach an equilibrium between location of work places and location of households every simulation period (Lowry 1964). Similarly, most models using Alonso's bid-rent approach (Alonso 1964) assume an immediate equilibrium between land prices and demand for land. Dynamic urban models, in contrast, explicitly represent time delay and limited information that lead to imperfect equilibriums (Harris and Wilson 1978; Wegener 1986). While bid-rent models are assumed to better represent land prices, discrete choice models often are expected to more realistically represent delays as they happen in reality. For example, newly demanded housing is not available to move into right away, as planning, obtaining building permits, and construction may take more than a year from when the demand is realized to when the first household may move in.

Wegener (2014, p. 753-755) identified three principal challenges for land-use modeling: represent environmental impacts, decline rather than growth, and the impacts of the future energy crises. Test- 
ing policies that address environmental impacts, such as carbon taxes, road pricing, or energy-efficient buildings have an immediate impact on household budgets. Planning for decline requires reallocating limited resources, including closing of schools or redevelopment of brownfield sites. A future energy crisis may limit the availability of fossil fuels for transportation or heating and cooling, with an immediate impact on household mobility and budgets. If these challenges hold true, representing constraints will become even more important. If models miss representing changes in travel behavior and location choice under increasing transportation costs, model results will be less realistic and difficult to defend. If congestion worsens and people spend more time traveling, models that miss adjusting destination choice, mode choice, and trip chaining will produce unlikely results. Representing constraints rather than the entire map of opportunities will become more important in a scarce energy future.

\section{Acknowledgements}

This research was funded in part by the Maryland Department of Transportation. An earlier version of SILO was developed with research funding of Parsons Brinckerhoff, Inc. Important input for model design and development were provided by Rick Donnelly, Greg Erhardt, and Chris Frazier. 


\section{References}

Abraham, J. E., and J. D. HUNT. 1999. Firm location in the MEPLAN model of Sacramento. Transportation Research Record 1685: 187-198.

Alonso, W. 1964. Location and Land Use. Towards a General Theory of Land Rent. Cambridge, MA: Harvard University Press.

Anas, A. 1982. Residential Location Markets and Urban Transportation. Economic Theory, Econometrics, and Policy Analysis with Discrete Choice Models. New York: Academic Press.

Arentze, T., and H. Timmermans. 2000. ALBATROSS-A Learning Based Transportation Oriented Simulation System. Eindhoven, the Netherlands: European Institute of Retailing and Services Studies.

Batty, M. 1976. Urban Modeling. Algorithms, Calibrations, Predictions. London: Cambridge University Press.

Clarke, M., and E. Holm. 1987. Microsimulation methods in spatial analysis and planning. Geografiska Annaler. Series B. Human Geography 69 B: 145-164.

Conder, S., and K. Lawton. 2002. Alternative futures for integrated transportation and land-use models contrasted with trend-delphi models. Transportation Research Record 1805: 99-107.

Cyganski, R., E. Fradedrich, and B. Lenz. 2015. Travel-time valuation for automated driving: A usecase-driven study. Annual Meeting of the Transportation Research Board. January 11-15, Washington, DC.

de la Barra, T. 1989. Integrated Land Use And Transport Modeling. Decision Chains and Hierarchies/ Cambridge, UK: Cambridge University Press.

de la Barra, T., B. Pérez, and N. Vera. 1984. TRANUS-J: Putting large models into small computers. Environment and Planning B: Planning and Design 11: 87-101.

de la Barra, T., and P. A. Rickaby. 1982. Modeling regional energy-use: A land-use, transport, and energy-evaluation model. Environment and Planning B: Planning and Design 9: 429-443.

Domencich, T. A., and D. McFadden. 1975. Urban Travel Demand. A Behavioral Analysis. Amsterdam: Oxford, North-Holland Publishing.

Echenique, M. H., D. Crowther, and W. Lindsay. 1969. A spatial model of urban stock and activity. Regional Studies 3: 281-312.

Echenique, M. H., A. D. J. Flowerdew, J. D. Hunt, T. R. Mayo, I. J., Skidmore. and D. C. Simmonds. 1990. The MEPLAN models of Bilbao, Leeds and Dortmund. Transport Reviews 10: 309-322.

Ettema, D., K. de Jong, H. Timmermans, and A. Bakema. 2004. PUMA (predicting urbanization with multi-agents): A multi-agent approach to modeling urban development and processes. Integrated assessment of the land system: The future of land use, October 28-30, 2004 Amsterdam.

Forrester, J. W. 1969. Urban Dynamics. Cambridge, MA: M.I.T. Press.

Goldner, W., S. R. Rosenthal, and J. R. Meredith. 1972. Theory and Application: Projective Land Use Model. Berkeley, CA: Institute of Transportation and Traffic Engineering.

Gregor, B. 2006. The land use scenario Developer (LUSDR): A practical land-use model using a stochastic microsimulation framework. 86th Annual Meeting of the Transportation Research Board, January 21-25, Washington, DC.

Harris, B. J., and A. G. Wilson. 1978. Equilibrium values and dynamics of attractiveness terms in production-constrained spatial-interaction models. Environment and Planning A 10: 371-388.

Herbert, J. D., and B. H. Stevens. 1960. A model for the distribution of residential activity in urban areas. Journal of Regional Science 2: 21-36.

Hunt, J. D., and J. E. Abraham. 2003. Design and application of the PECAS land-use modeling system. 
8th International Conference on Computers in Urban Planning and Urban Management. Dates, Sendai, Japan.

Hunt, J. D., and J. E. Abraham. 2009. PECAS—for Spatial Economic Modeling. Calgary, Alberta: HBA Specto Incorporated.

Hunt, J. D., D. S. Kriger, and E. J. Miller. 2005. Current operational urban land-use/transport modelling frameworks: A review. Transport Reviews 25: 329-376.

Kain, J. F. 1987. Computer simulation models of urban location. In Handbook of Regional and Urban Economics. Volume II: Urban Economics, edited by E. S. Mills. Amsterdam: North-Holland.

Kanaroglou, P. S., and D. M. Scott. 2002. Integrated urban transportation and land-use models for policy analysis. In Governing Cities on the Move. Functional and Management Perspectives on Transformations of European Urban Infrastructures, edited by M. Dijst, W. Schenkel, and I. Thomas. Hamshire England: Ashgate.

Landis, J., and M. Zhang. 1998a. The second generation of the California urban futures model. Part 1: Model logic and theory. Environment and Planning B: Planning and Design 25: 657-666.

Landis, J., and M. Zhang. 1998b. The second generation of the California urban futures model. Part 2: Specification and calibration results of the land-use change submodel. Environment and Planning B: Planning and Design 25: 795-824.

Litman, T. 2013. Changing North American vehicle-travel price sensitivities: Implications for transport and energy policy. Transport Policy 28: 2-10.

Lowry, I. S. 1964. A Model of Metropolis. Memorandum RM-4035-RC. Santa Monica, CA: Rand Corporation.

Lowry, I. S. 1966. Migration and Metropolitan Growth: Two Analytical Models. San Francisco: Chandler.

Martínez, F. J. 1992. The bid-choice land-use model: An integrated economic framework. Environment and Planning A 24: 871-885.

Martínez, F. J. 1996. MUSSA: Land use model for Santiago City. Transportation Research Record 1552: 126-134.

Martínez, F. J. 2002. Towards a land-use and transport interaction framework. In Handbook of Transport Modeling, second edition, edited by D. A. Hensher, and K. J. Button. Amsterdam: Pergamon.

McFadden, D. 1978. Modeling the choice of residential location. In Spatial Interaction Theory and Planning Models, edited by A. Karkqvist, L. Lundqvist, F. Snickars, and J. W. Weibull. Amsterdam, New York, Oxford: North-Holland Publishing Company.

Miller, E. J., J. D. Hunt, J. E. Abraham, and P. A. Salvini. 2004. Microsimulating urban systems. Computers, Environment and Urban Systems 28: 9-44.

Miller, E. J., and P. A. Salvini. 2001. The integrated land use, transportation, environment (ILUTE) microsimulation modeling system: Description and current status. In Travel Behavior Research. The Leading Edge, edited by D. A. Hensher. Amsterdam: Pergamon.

Mishra, S., X. Ye, F. Ducca, and G. J. Knaap. 2011. A functional integrated land-use/transportation model for analyzing transportation impacts in the Maryland-Washington, DC region. Sustainability: Science, Practice, and Policy 7: 60-69.

Orcutt, G. H., M. Greenberger, J. Korbel, and A. M. Rivlan. 1961. Microanalysis of Socioeconomic Systems: A Simulation Study. New York: Harper and Brothers.

Putman, S. H. 1983. Integrated Urban Models. Policy Analysis of Transportation and Land Use. London: Pion.

Putman, S. H. 1991. Integrated Urban Models 2. New Research and Applications of Optimization And Dynamics. London: Pion.

Reynolds, M. M., and J. R. Meredith. 1972. Computer Systems Guide: Projective Land Use Model. Berke- 
ley, CA: Institute of Transportation and Traffic Engineering.

Rosenthal, S. R., J. R. Meredith, and W. Goldner. 1972. Plan making with a computer model: Projective land-use model. Berkeley, CA: Institute of Transportation and Traffic Engineering.

Salvini, P. A., and E. J. Miller. 2003. ILUTE: An operational prototype of a comprehensive microsimulation model of urban systems. 10th International Conference on Travel Behaviour Research, August 10-15, Lucerne.

Simmonds, D. C., and O. Feldman. 2007. Advances in integrated urban/regional land-use/transport modeling using the DELTA package. World Conference on Transport Research. June 24-28, Berkeley, CA.

Strauch, D., R. Moeckel, M. Wegener, J. Gräfe, H. Mühlhans, G. Rindsfüser, and K. J. Beckmann. 2005. Linking transport and land-use planning: The Microscopic dynamic simulation model ILUMASS. In GeoDynamics, edited by P. M. Atkinson, G. M. Foody, S. E. Darby, and F. Wu. Boca Raton, FL: CRC Press.

Timmermans, H. 2003. The saga of integrated land use-transport modeling: How many more dreams before we wake up? Moving through nets: The physical and social dimensions of travel. 10th International Conference on Travel Behavior Research, August 10-15, Lucerne, Switzerland.

US Environmental Protection Agency. 2000. Projecting Land-Use Change. A Summary of Models for Assessing the Effects of Community Growth and Change on Land-Use Patterns. Cincinnati, OH: Environmental Protection Agency, Office of Research and Development.

Van Wissen, L. J., T. F. Golob, and H. J. Meurs. 1991. A Simultaneous Dynamic Travel And Activities Time Allocation Model. Berkeley, CA: University of California Transportation Center: Faculty Research.

Waddell, P. 2002. UrbanSim. Modeling urban development for land-use, transportation, and environmental planning. Journal of the American Planning Association 68: 297-314.

Waddell, P., A. Borning, M. Noth, N. Freier, M. Becke, and G. F. Ulfarsson. 2003. Microsimulation of urban development and location choice: Design and implementation of UrbanSim. Networks and Spatial Economics 3: 43-67.

Wagner, P., and M. Wegener. 2007. Urban land-use, transport and environment models. Experiences with an integrated microscopic approach. dis $P$ 170: 45-56.

Wang, F. 1998. Urban population distribution with various road networks: A simulation approach. Environment and Planning B: Planning and Design 25: 265-278.

Wegener, M. 1982. Modeling urban decline: A multilevel economic-demographic model for the Dortmund region. International Regional Science Review 7: 217-241.

Wegener, M. 1984. Räumliches Wahlverhalten unter ökonomischen und informationellen Restriktionen: Ein mikroanalytisches Modell des Wohnungsmarkts. In Theorie und Quantitative Methodik in der Geographie, edited by G. Bahrenberg and M. M. Fischer. Bremen, Germany: Universität Bremen.

Wegener, M. 1986. Transport network equilibrium and regional deconcentration. Environment and Planning A 18: 437-456.

Wegener, M. 1994. Operational urban models. Journal of the American Planning Association 60: 17-29.

Wegener, M. 1998a. Applied models of urban land use, transport and environment: State-of-the-art and future developments. In Network Infrastructure and the Urban Environment. Advances in Spatial Systems Modeling, edited by L. Lundqvist, L. G. Mattsson, and T. J. Kim. Berlin: Springer.

Wegener, M. 1998b. The IRPUD Model: Overview http://www.spiekermann-wegener.com/mod/ irpudmod_e.htm.

Wegener, M. 1999. Die Stadt der kurzen Wege: Müssen wir unsere Städte umbauen? Dortmund, Ger- 
many: Institut für Raumplanung.

Wegener, M. 2004. Overview of land-use transport models. In Handbook of Transport Geography And Spatial Systems, edited by D. A. Hensher, K. J. Button, K. E. Haynes, and P. R. Stopher. Amsterdam: Elsevier.

Wegener, M. 2014. Land-use transport interaction models. In Handbook of Regional Science, edited by M. Fischer and P. Nijkamp. Berlin: Springer.

Wegener, M., and F. Fürst. 1999. Land-Use Transport Interaction: State-of-the-Art. Dortmund, Germany: Institut für Raumplanung.

Wegener, M., F. Gnad, and M. Vannahme. 1986. The time scale of urban change. In Advances in Urban Systems Modeling, edited by B. Hutchinson, and M. Batty. Amsterdam: Elsevier Science Publishers B.V. (North-Holland).

Wilson, A. G. 1967. Statistical theory of spatial distribution models. Transportation Research 1:253-269. Wilson, A. G. 1970. Entropy in Urban and Regional Modeling. London, Pion.

Zahavi, Y., M. J. Beckmann, and T. F. Golob. 1981. The UMOT/Urban Interactions. Washington DC: U.S. Department of Transportation. 